\title{
CHEMOSPHERE
}

\section{Decomposition of 2-mercaptothiazoline in aqueous solution by ozonation}

\author{
Y.H. Chen ${ }^{\text {a }}$, C.Y. Chang ${ }^{\text {a,* }}$, C.C. Chen ${ }^{\text {a }}$, C.Y. Chiu ${ }^{\text {b }}$, Y.H. Yu ${ }^{\text {a }}$, \\ P.C. Chiang ${ }^{\mathrm{a}}$, Y. Ku ${ }^{\mathrm{c}}$, J.N. Chen ${ }^{\mathrm{d}}$, C.F. Chang ${ }^{\mathrm{a}}$ \\ ${ }^{a}$ Graduate Institute of Environmental Engineering, National Taiwan University, 71 Chou-Shan Road, Taipei 106, Taiwan \\ ${ }^{\mathrm{b}}$ Department of Environmental Engineering, Lan-Yang Institute of Technology, I-Lan 261, Taiwan \\ ${ }^{\mathrm{c}}$ Department of Chemical Engineering, National Taiwan University of Science and Technology, Taipei 106, Taiwan \\ ${ }^{\mathrm{d}}$ Graduate Institute of Environmental Engineering, National Chiao-Tung University, Hsin-Chu 300, Taiwan
}

Received 11 June 2003; received in revised form 31 October 2003; accepted 5 February 2004

\begin{abstract}
This study investigates the ozonation of 2-mercaptothiazoline (2-MT). The 2-MT is one of the important organic additives for the electroplating solution of the printed wiring board industry and has been widely used as a corrosion inhibitor in many industrial processes. It is of concern for the aquatic pollution control especially in the wastewaters. Semibatch ozonation experiments in the completely stirred tank reactor are performed under various concentrations of input ozone. The concentrations of 2-MT, sulfate, and ammonium are analyzed at specified time intervals to elucidate the decomposition of 2-MT during the ozonation. In addition, the time variation of the dissolved ozone concentration $\left(C_{\mathrm{ALb}}\right)$ is continuously monitored in the course of experiments. Total organic carbon (TOC) is chosen and measured as a mineralization index of the ozonation of 2-MT. The results indicate that the decomposition of 2-MT is efficient, while the mineralization of TOC is limited via the ozonation only. Simultaneously, the yield of sulfate with the maximum value of about $47 \%$ is characterized by the increases of TOC removal and ozone consumption. These results can provide some useful information for assessing the feasibility of the treatment of 2-MT in the aqueous solution by the ozonation.
\end{abstract}

(C) 2004 Elsevier Ltd. All rights reserved.

Keywords: Ozone; 2-Mercaptothiazoline; Sulfate; Total organic carbon; Water treatment

\section{Introduction}

Organic corrosion inhibitors, such as thiourea, phenylthiourea, and 2-mercaptothiazoline (2-MT), have been used for the protection against corrosion in many industrial processes (Wang et al., 2001). The combination of an exocyclic thione group and a heterocyclic molecule, which may contain nitrogen, carbon, and sulfur atoms, generates a group of compounds with

\footnotetext{
${ }^{*}$ Corresponding author. Tel./fax: +886-2-2363-8994.

E-mail address: cychang3@ntu.edu.tw (C.Y. Chang).
}

considerably coordinational potential (Lizarraga et al., 1997). Accordingly, these inhibitors have been frequently detected in wastewater effluents as well as river water (Fiehn et al., 1998). Furthermore, most of them are of high mobility within the aquatic system. Among them, 2-MT with a five-member heterocyclic ring has been commonly used as biocorrosion inhibitor, antifungal in medical application, and coating agent of metallic surfaces attributed to its adsorption or complexation on the surface of metal associated with the electron donor properties of $\mathrm{N}$ or $\mathrm{S}$ atoms (Mahal and Mukherjee, 1999). It has been also used as a brightening and stabilization agent in the electroplating solution of 
printed wiring board industry (Fang, 1996). The 2-MT is harmful according to its Material Safety Data Sheet. Thus, 2-MT is of concern as an aqueous pollutant in water and wastewater treatment.

Ozonation is considered as an effective way to reduce the total organic carbons (TOCs) by oxidizing the stream solutions with ozone (Koch et al., 2002). Ozone may attack on the pollutants via two different reaction pathways: (1) the direct ozonation by the ozone molecule, and (2) the radical ozonation by the highly oxidative free radicals such as hydroxyl free radicals, which are formed by the decomposition of ozone in the aqueous solution (Gurol and Singer, 1982; Sotelo et al., 1987). The radical ozonation is non-selective and vigorous. The ozonation process in the acid condition mainly takes place through the direct oxidation reaction, which is selective (Beltrán and Alvarez, 1996; Hautaniemi et al., 1998).

However, the information about the ozonation of 2MT is found scarce and desirable. The objective of this study is to examine the phenomena during the ozonation of 2-MT. Semibatch ozonation experiments in the completely stirred tank reactor are proceeded under various concentrations of input ozone. The concentrations of 2-MT, sulfate, and ammonium are analyzed at specified time intervals to study the decomposition of 2-MT. TOC is chosen as a mineralization index of the ozonation of 2-MT. Moreover, the values of the dissolved ozone concentration $\left(C_{\mathrm{ALb}}\right)$ and $\mathrm{pH}$ are measured continuously in the course of experiments.

\section{Materials and methods}

\subsection{Chemicals}

The initial concentration $\left(C_{\mathrm{B} 0}\right)$ of aqueous solution consisting of 2-MT as the only organic target is 100 $\mathrm{mgl}^{-1}$. The 2-MT with chemical formula of $\mathrm{C}_{3} \mathrm{H}_{5} \mathrm{NS}_{2}$, which was purchased from Aldrich (Milwankee, WI, USA) and used without any further purification, has molecular weight of 119.21, melting point of 105-107 ${ }^{\circ} \mathrm{C}$, and CAS registry number of 96-53-7. The molecular structure of 2-MT is shown in Fig. 1. All solutions used for the experiments were prepared with deionized water without buffers. The initial values of $\mathrm{pH}$ and TOC

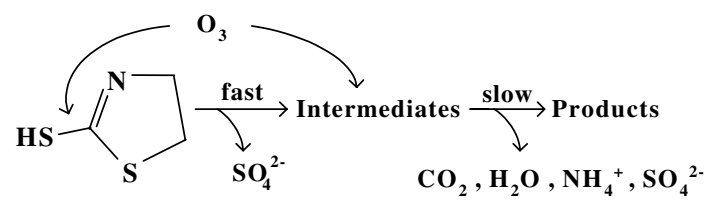

Fig. 1. Molecular structure of 2-mercaptothiazoline (2-MT) and simplified scheme of decomposition of 2-MT via ozonation.
$\left(C_{\mathrm{TOC} 0}\right)$ of solution were measured as 5.50 and 29.1 $\mathrm{mgl}^{-1}$, respectively. The volatility of $2-\mathrm{MT}$ in the aqueous solution was demonstrated to be negligible from the air-stripping test.

\subsection{Instrumentation}

The airtight reactor with inside diameter of $17.2 \mathrm{~cm}$ was made of Pyrex glass with an effective volume of 5.5 1. It was equipped with water bath jacket to maintain a constant solution temperature at $25{ }^{\circ} \mathrm{C}$ in all experiments. The design of reactor was based on the criteria of the shape factors of a standard six-blade turbine (McCabe et al., 1993). The gas diffuser in cylindrical shape with pore size of $10 \mu \mathrm{m}$ was located at the bottom of the reactor. About 3.7051 solution $\left(V_{\mathrm{L}}\right)$ was used in each experiment. The total sampling volumes were within $5 \%$ of the solution. The stirred speed was kept as high as 800 rpm to ensure the completely mixing of liquid and gas according to the previous tests (Chang et al., 2001). The generation of ozone was controlled by the power input of the ozone generator (model SG-01A, Sumitomo, Tokyo, Japan) with constant gas pressure $\left(1 \mathrm{kgf} \mathrm{cm}^{-2}\right)$. The ozone generator used in this research employed two steel plate electrodes with ceramic dielectric medium. Ozonecontaining gas generated by pure oxygen was introduced into the reactor with a gas flow rate $\left(Q_{\mathrm{G}}\right)$ of $1.781 \mathrm{~min}^{-1}$ at $273 \mathrm{~K}, 1 \mathrm{~atm}$.

\subsection{Analytical method}

The input $\left(C_{\mathrm{AGi} 0}\right)$ and outlet $\left(C_{\mathrm{AGe}}\right)$ gas ozone concentrations were measured by an UV photometric analyzer (Seki, model SOZ-6004, Tokyo, Japan), which was calibrated by the KI titration method (Rankness et al., 1996). The Orbisphere's model 3600 liquid ozone monitor with a sensor of membrane-containing cathode, which was calibrated by the indigo method, was used to analyze the dissolved ozone concentration $\left(C_{\mathrm{ALb}}\right)$ in the aqueous solution. The $\mathrm{pH}$ meter (model 300T, Suntex, Taipei, Taiwan) was used to measure the $\mathrm{pH}$ value of the solution. A circulation pump was used to transport the liquid from the reactor to pass through the sensors with a flow rate of $0.181 \mathrm{~min}^{-1}$, and to re-circulate it back during the ozonation. All fittings, tubings, and bottles were made of stainless steel, Teflon, or glass.

Samples were drawn out from the reactor at desired time intervals in the course of experiments. The residual dissolved ozone in the sample was removed by nitrogen gas stripping. The concentrations of 2-MT $\left(C_{\mathrm{B}}\right)$ were analyzed using high performance liquid chromatography (HPLC) system equipped with $250 \times 4.6 \mathrm{~mm}$ column (model BDS C18 $(5 \mu \mathrm{m})$, Thermo Hypersil-keystone, Bellfonte, PA, USA), and UV/Visible detector (model 1706, Bio-Rad, Hercules, CA, USA) at $275 \mathrm{~nm}$. The HPLC effluent with flow rate of $1.0 \mathrm{ml} \mathrm{min}^{-1}$ had the 


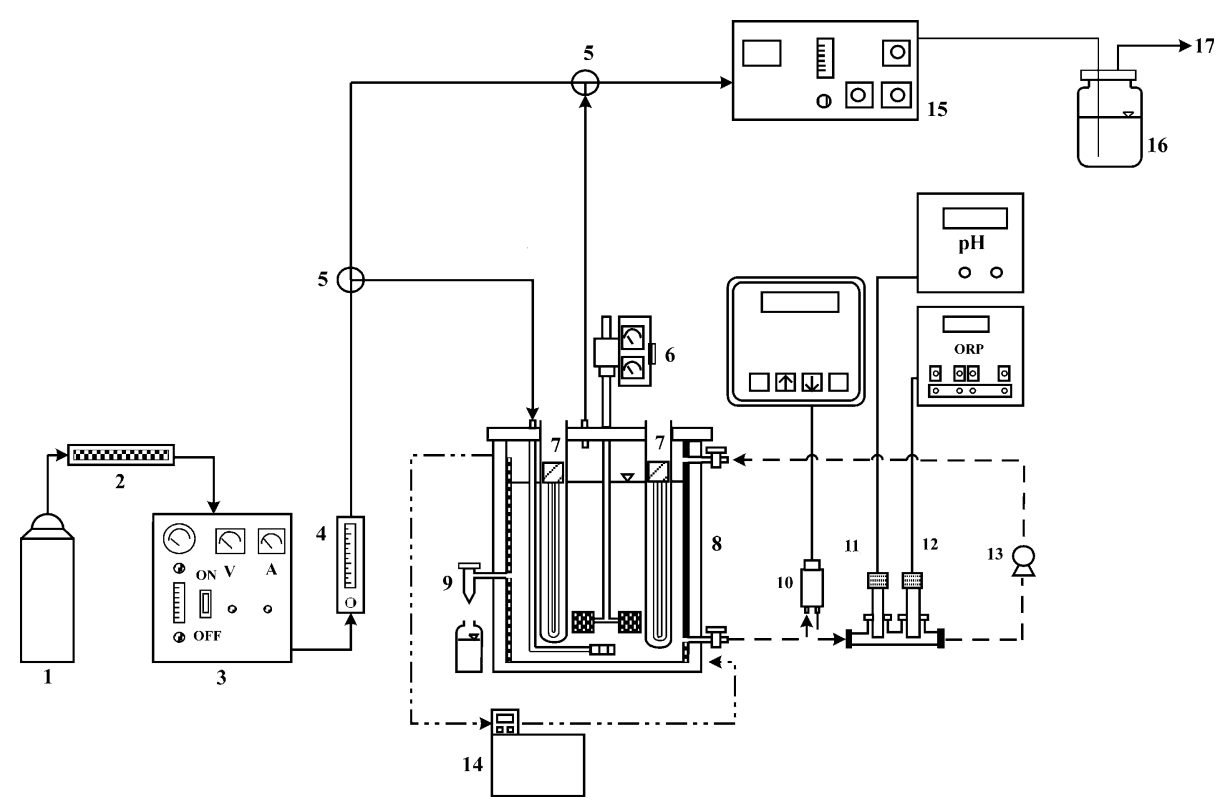

Fig. 2. Experimental apparatus sketch. _ _, - - _- - : ozone gas stream, experimental solution, isothermal water. Components: 1. oxygen cylinder, 2. drying tube, 3. ozone generator, 4. flow meter, 5. three-way valves, 6. stirrer, 7. lamps, 8. reactor, 9. sample port, 10. liquid ozone sensor, 11. $\mathrm{pH}$ sensor, 12. oxidation reduction potential (ORP) sensor, 13. circulation pump, 14. thermostat, 15. gas ozone detector, 16. KI solution, 17. vent to hood.

composition with $73.5 \mathrm{mM}\left[\mathrm{CH}_{3}\left(\mathrm{CH}_{2}\right)_{3}\right]_{4} \mathrm{~N}\left(\mathrm{HSO}_{4}\right)$ : $\mathrm{CH}_{3} \mathrm{CN}$ of $74: 26$. The injection volume of analytic solution was $20 \mu$. The detection limit of $C_{\mathrm{B}}$ was 0.01 $\mathrm{mgl} \mathrm{l}^{-1}$. The ionic chromatography (IC) employed to analyze the anionic concentrations of sulfate $\left(C_{\mathrm{SO}_{4}^{2-}}\right)$ and nitrate $\left(C_{\mathrm{NO}_{3}^{-}}\right)$was equipped with $150 \times 5.5 \mathrm{~mm}$ column (model AN300, MetaChem, Lake forest, CA, USA) and detector (model conductivity series IV, LabAlliance, Lemont, PA, USA). The effluent with flow rate of 2.0 $\mathrm{mlmin}{ }^{-1}$ had the composition with $\mathrm{NaHCO}_{3} / \mathrm{Na}_{2} \mathrm{CO}_{3}$ of $1.7 \mathrm{mM} / 1.8 \mathrm{mM}$. The IC employed to analyze the cationic concentrations of ammonium $\left(C_{\mathrm{NH}^{+}}\right)$was equipped with $250 \times 4 \mathrm{~mm}$ column of model IonPac CS12A and detector of model CSRS-II (both with Dionex, Sunnyvale, CA, USA). The effluent with flow rate of $1.0 \mathrm{ml} \mathrm{min}^{-1}$ had the composition with $22 \mathrm{mM}$ $\mathrm{CH}_{4} \mathrm{O}_{3} \mathrm{~S}$. The TOC concentration $\left(C_{\mathrm{TOC}}\right)$ of sample was analyzed by the TOC analyzer (model 700, O.I. Corporation, TX, USA). The instrument employed the UVpersulfate technique to convert the organic carbon into carbon dioxide for the subsequent analysis by an infrared $\mathrm{CO}_{2}$ analyzer calibrated with the potassium hydrogen phthalate standard.

\subsection{Experimental procedures}

The semibatch experiments of 2-MT ozonation were performed to examine the time variations of $C_{\mathrm{ALb}}, C_{\mathrm{B}}$,
$C_{\mathrm{SO}_{+}^{2-}}, C_{\mathrm{NO}_{3}^{-}}, C_{\mathrm{NH}_{4}^{+}}, C_{\mathrm{TOC}}$, and $\mathrm{pH}$. Before starting the ozonation experiments, the ozone-containing gas was bypassed to the UV photometric analyzer to measure the ozone concentration and assure the stability. A part of gas stream at a preset flow rate was directed into the reactor when reaching the preset conditions. The experimental apparatus employed in this work is shown in Fig. 2.

\section{Results and discussion}

3.1. Time variations of $C_{A L b}, C_{B}, C_{S_{4}^{2-}}, C_{N_{4}^{+}}, C_{T O C}$, and $\mathrm{pH}$ in ozonation of $2-M T$

The variations of $C_{\mathrm{ALb}}, C_{\mathrm{B}}, C_{\mathrm{SO}_{4}^{2-}}, C_{\mathrm{NH}_{4}^{+}}, C_{\mathrm{TOC}}$, and $\mathrm{pH}$ with the ozonation time $(t)$ with $C_{\mathrm{AGi}}=40 \mathrm{mgl}^{-1}$ are shown in Fig. 3. The results indicate that the $C_{\mathrm{ALb}}$, $C_{\mathrm{SO}_{4}^{2-}}$, and $C_{\mathrm{NH}_{4}^{+}}$increase while the $C_{\mathrm{B}}, C_{\mathrm{TOC}}$, and $\mathrm{pH}$ decrease with the ozonation time. The time for the reduction of 2-MT below the detection limit denoted as $t_{\mathrm{f}, \mathrm{MT}}$ is a characteristic time of great concern during the ozonation of 2-MT. The comparison of ozonation results at $t_{\mathrm{f}, \mathrm{MT}}$ under various experimental conditions is summarized in Table 1. The $Y_{\mathrm{SO}_{4}^{2-}}\left(=C_{\mathrm{SO}_{4}^{2-}} /\left(2 C_{\mathrm{B} 0}\right)\right)$ and $\eta_{\mathrm{TOC}}\left(=\left(C_{\mathrm{TOC} 0}-C_{\mathrm{TOC}}\right) / C_{\mathrm{TOC}}\right)$ denote the percentage of yield of sulfate and removal efficiency of TOC, respectively. The units of $C_{\mathrm{SO}_{4}^{2-}}$ and $C_{\mathrm{B} 0}$ are in $\mathrm{M}$. 


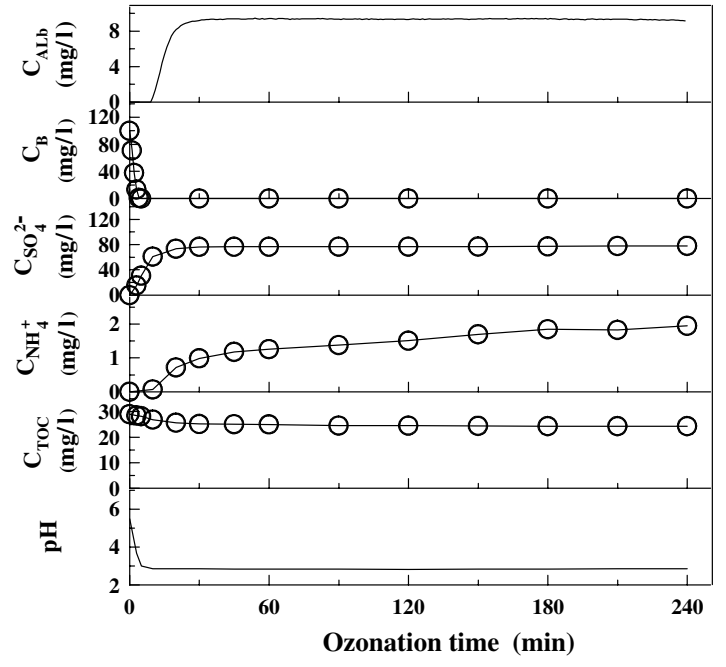

Fig. 3. Time variations of concentrations $\left(C_{\mathrm{ALb}}, C_{\mathrm{B}}, C_{\mathrm{SO}_{4}^{2-}}\right.$, $C_{\mathrm{NH}_{4}^{+}}, C_{\mathrm{TOC}}$ ), and $\mathrm{pH}$ for ozonation of 2-MT in semibatch system. Concentration of input ozone gas $\left(C_{\mathrm{AGi0}}\right)=40 \mathrm{mgl}^{-1}$.

Table 1

Comparison of ozonation results at specific times $\left(t_{\mathrm{f}, \mathrm{MT}}\right)$ for reduction of 2-MT below detection limit under various experimental conditions

\begin{tabular}{|c|c|c|c|c|}
\hline Experimental condition $^{\mathrm{a}}$ & $\begin{array}{l}t_{\mathrm{f}, \mathrm{MT}} \\
(\mathrm{min})\end{array}$ & $\begin{array}{l}Y_{\mathrm{SO}_{4}^{2-}} \\
(\%)\end{array}$ & $\begin{array}{l}\eta_{\text {TOC }} \\
(\%)\end{array}$ & $\mathrm{pH}$ \\
\hline $\begin{array}{l}\text { Case } 1 C_{\text {AGi0 }}=10 \\
\mathrm{mg} \mathrm{l}^{-1}\end{array}$ & 15 & 24 & 1.6 & 3.09 \\
\hline $\begin{array}{l}\text { Case } 2 C_{\text {AGi } 0}=20 \\
\mathrm{mgl}^{-1}\end{array}$ & 10 & 29 & 2.5 & 3.04 \\
\hline $\begin{array}{l}\text { Case } 3 C_{\mathrm{AGi} 0}=40 \\
\mathrm{mg} \mathrm{l}^{-1}\end{array}$ & 5 & 19 & 2.7 & 3.01 \\
\hline
\end{tabular}

${ }^{\mathrm{a}}$ Initial values of $C_{\mathrm{B} 0}, C_{\mathrm{TOC}}$, and $\mathrm{pH}$ are $100 \mathrm{mg} \mathrm{l}^{-1}, 29.1$ $\mathrm{mgl}^{-1}$, and 5.50, respectively.

The results illustrate that the decomposition of 2-MT accompanies with the noteworthy generation of sulfate while with the low diminution of TOC. The values of $Y_{\mathrm{SO}_{4}^{2-}}$ at $t_{\mathrm{f}, \mathrm{MT}}$ are about $24 \pm 5 \%$ for the three cases examined. The intermediates generated from the ozonation of 2-MT at $t_{\mathrm{f}, \mathrm{MT}}$ still contribute over $97 \%$ of the initial TOC (Table 1). Nevertheless, the TOC value gradually decreases with further oxidation of successive products formed. In addition, the $\mathrm{pH}$ value of the solution decreases rapidly in the early period $\left(t<t_{\mathrm{f}, \mathrm{MT}}\right)$ and then approaches a constant value as the ozonation time increases. The increase of acidity (decrease of $\mathrm{pH}$ value) follows the generation of sulfate because one sulfate molecule is associated with two protons. Note that the theoretical $\mathrm{pH}$ value at $t_{\mathrm{f}, \mathrm{MT}}$ is calculated as 3.09 for the average value of $Y_{\mathrm{SO}_{4}^{2-}}$ of $24 \%$, closing to the experimental $\mathrm{pH}$ values of $3.01-3.09$ as indicated in
Table 1. Moreover, the value of $C_{\mathrm{ALb}}$ remains low in the early ozonation period and then increases rapidly in a short time. A small quantity of ammonium is detected during the ozonation of 2-MT.

\subsection{Decomposition of 2-MT and formation of sulfate and ammonium}

The effect of the input ozone dosage on the decomposition of 2-MT is shown in Fig. 4. The value of $t_{\mathrm{f}, \mathrm{MT}}$ with $C_{\mathrm{AGi}}=40 \mathrm{mgl}^{-1}(5 \mathrm{~min})$ is one-third and one-half of those with $C_{\mathrm{AGi}}=10\left(t_{\mathrm{f}, \mathrm{MT}}=15 \mathrm{~min}\right)$ and $20 \mathrm{mg} \mathrm{l}^{-1}$ $\left(t_{\mathrm{f}, \mathrm{MT}}=10 \mathrm{~min}\right)$, respectively. Further, the pseudo-first order rate constant $\left(k_{\mathrm{B}}\right)$ for the expression of $C_{\mathrm{B}} / C_{\mathrm{B} 0}=$ $\mathrm{e}^{-k_{\mathrm{B}} t}$ can be obtained yielding $k_{\mathrm{B}}=0.0167 C_{\mathrm{AGi}} \mathrm{min}^{-1}$ (with $\mathrm{C}_{\mathrm{AGi0}}$ in $\mathrm{mg}^{-1}$ ) from the experimental data. We may note that the mercapto substituent, which is an electron donor, has a high reactivity with ozone molecules toward the electrophilic reaction (Langlais et al., 1991). Referring to the ozonation mechanism of 2-mercaptobenzothiazole reported by Fiehn et al. (1998), we can propose a simplified scheme for the decomposition of 2-MT via the ozonation as shown in Fig. 1. The initial attack of ozone on 2-MT is mainly toward the mercapto group to generate sulfate. The value of $Y_{\mathrm{SO}_{4}^{2-}}$ would be close to $50 \%$ when all the sulfur atoms of the mercapto substitute are oxidized to sulfate. Thus, we can estimate that only nearly a half of the sulfur atoms of the mercapto substituent has been oxidized to form sulfate at $t_{\mathrm{f}, \mathrm{MT}}$, with average value of $Y_{\mathrm{SO}_{4}^{2-}}$ of $24 \%$ (Table 1).

As shown in Fig. 5, which illustrates the time variation of $Y_{\mathrm{SO}_{4}^{2-}}$, the generation rate of sulfate is accelerated by the input ozone dosage. The $Y_{\mathrm{SO}_{4}^{2-}}$ approaches constant values of about $45-48 \%$ in 30 to $90 \mathrm{~min}$ for the

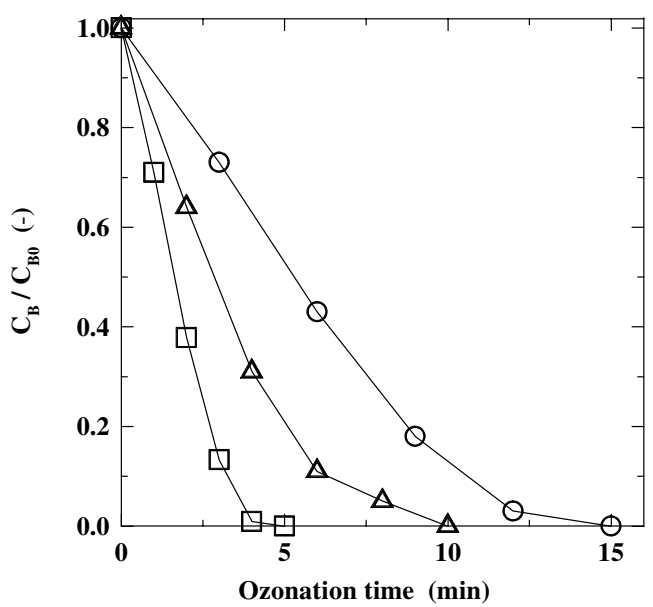

Fig. 4. Time variation of $C_{\mathrm{B}} / C_{\mathrm{B} 0}$ for ozonation of $2-\mathrm{MT}$ in semibatch system. $\mathrm{O}, \triangle$, and $\square: C_{\mathrm{AGi} 0}=10,20$, and $40 \mathrm{mg} \mathrm{l}^{-1}$. $C_{\mathrm{B} 0}=C_{\mathrm{B}}$ at $t=0$. 


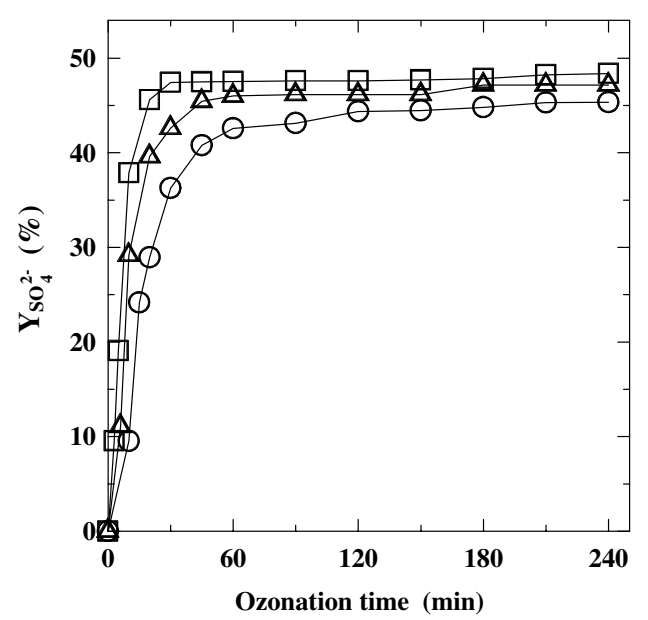

Fig. 5. Time variation of $Y_{\mathrm{SO}_{4}^{2-}}$ for ozonation of 2-MT in semibatch system. $Y_{\mathrm{SO}_{4}^{2-}}=C_{\mathrm{SO}_{4}^{2-}} /\left(2 C_{\mathrm{B} 0}\right)\left(\mathrm{MM}^{-1}\right)$. Notations are the same as specified in Fig. 4.

cases examined. Furthermore, the broken mercapto group may probably form hydrogen sulfide, which is a weak acid (with $\mathrm{p} K_{\mathrm{a}_{1}}=7.0$ and $\mathrm{p} K_{\mathrm{a}_{2}}=13.9$ ) and has high volatility $\left(\mathrm{H}_{2} \mathrm{~S}_{(\mathrm{aq})} \leftrightarrow \mathrm{H}_{2} \mathrm{~S}_{(\mathrm{g})}\right.$ with $\mathrm{pK}$ of $\mathrm{H}_{2} \mathrm{~S}_{(\mathrm{aq})}=$ 1.01) (Morel and Hering, 1993). Some hydrogen sulfide would then be stripped from the aqueous solution by the gas stream continuously introduced before being oxidized. This cause thus makes the value of $Y_{\mathrm{SO}_{4}^{2-}}$ a little smaller than $50 \%$. The results also reveal that the sulfur atom of the heterocyclic ring is hard to be oxidized. In addition, the generation of sulfate $\left(Y_{\mathrm{SO}_{4}^{2-}}\right)$ is found consistent with the increase of $\eta_{\text {TOC }}$ for the ozonation of 2-MT as depicted in Fig. 6. The value of $Y_{\mathrm{SO}_{4}^{2-}}$ increases rapidly with $\eta_{\text {TOC }}$ when $\eta_{\text {TOC }}<10 \%$. For $\eta_{\text {TOC }} \geqslant 10 \%$, the formation rate of sulfate becomes slow with $Y_{\mathrm{SO}_{4}^{2-}}$ greater than $40 \%$.

In a study on the ozonation of pyridine homologs, Wibaut (1959) reported that the $\mathrm{C}=\mathrm{N}$ bond does not react with ozone directly, but rather undergoes hydrolytic splitting to form ammonia during the decomposition of ozonide. In the present study, ammonium is also detected in the later period of the ozonation of 2-MT. The concentration of ammonium, although having a low reactivity with ozone (Hoigné et al., 1985), increases with the ozonation time. The percentage of conversion of ammonium $\left(C_{\mathrm{NH}_{4}^{+}} / C_{\mathrm{B} 0}, \mathrm{MM}^{-1}\right)$ reaches $13 \%$ at $t=240 \mathrm{~min}$ with $C_{\mathrm{AGi0}}=40 \mathrm{mg} \mathrm{l}^{-1}$, which is close to the value of $\eta_{\mathrm{TOC}}$ of $16 \%$ while smaller than that of $Y_{\mathrm{SO}_{4}^{2-}}$ of $48 \%$. This may be due to the cause that the $C_{\mathrm{NH}_{4}^{+}}$and $\eta_{\text {TOC }}$ depend on the destruction of the heterocyclic molecule, while the $Y_{\mathrm{SO}_{4}^{2-}}$ is mainly generated from the oxidation of the mercapto group. However, the nitrate concentration $\left(C_{\mathrm{NO}_{3}^{-}}\right)$is detected below the detection limit of $0.01 \mathrm{mg}^{-1}$.

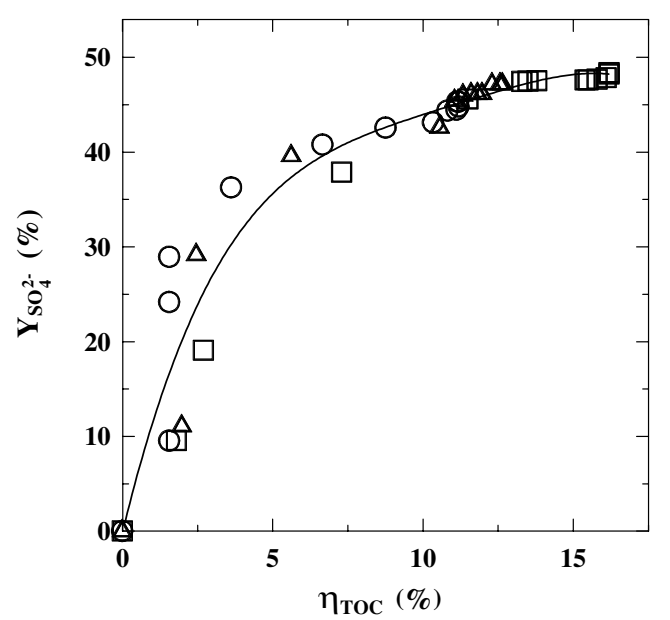

Fig. 6. $Y_{\mathrm{SO}_{4}^{2-}}$ vs. $\eta_{\mathrm{TOC}}$ for ozonation of 2-MT in semibatch system. $\eta_{\mathrm{TOC}}=\left(C_{\mathrm{TOC} 0}-C_{\mathrm{TOC}}\right) / C_{\mathrm{TOC} 0}, C_{\mathrm{TOC} 0}=C_{\mathrm{TOC}}$ at $t=0$. Notations are the same as specified in Fig. 4. - : polynomial curve fitting of experimental data with $R^{2}=0.939$, where $R^{2}$ $($ determination coefficient $)=1-\left[\sum\left(C_{\mathrm{e}}-C_{\mathrm{p}}\right)^{2} / \sum\left(C_{\mathrm{e}}-\bar{C}_{\mathrm{e}}\right)^{2}\right]$. $C_{\mathrm{e}}, \bar{C}_{\mathrm{e}}=$ experimental data and corresponding average value. $C_{\mathrm{p}}=$ predicted values.

\subsection{Removal of TOC associated with variation of $C_{A L b}$}

For an illustration on the effect of $C_{\mathrm{AGi}}$ on the elimination of TOC, Fig. 7 shows the variation of mean mineralization rate, $\left(C_{\mathrm{TOC} 0}-\mathrm{C}_{\mathrm{TOC}}\right) / t$, with $\eta_{\mathrm{TOC}}$. The results reveal that the input ozone dosage proportionally enhances the mineralization rate of 2-MT. For example, the average values of $\left(C_{\mathrm{TOC} 0}-C_{\mathrm{TOC}}\right) / t$ with $C_{\mathrm{AGi}}=10$, 20 , and $40 \mathrm{mgl}^{-1}$ for $\eta_{\mathrm{TOC}}=0-10 \%$ are about 0.037 , 0.088 , and $0.18 \mathrm{mg} \mathrm{l}^{-1} \mathrm{~min}^{-1}$, respectively. However, the values of $\left(C_{\mathrm{TOC} 0}-\mathrm{C}_{\mathrm{TOC}}\right) / t$ for all cases decrease

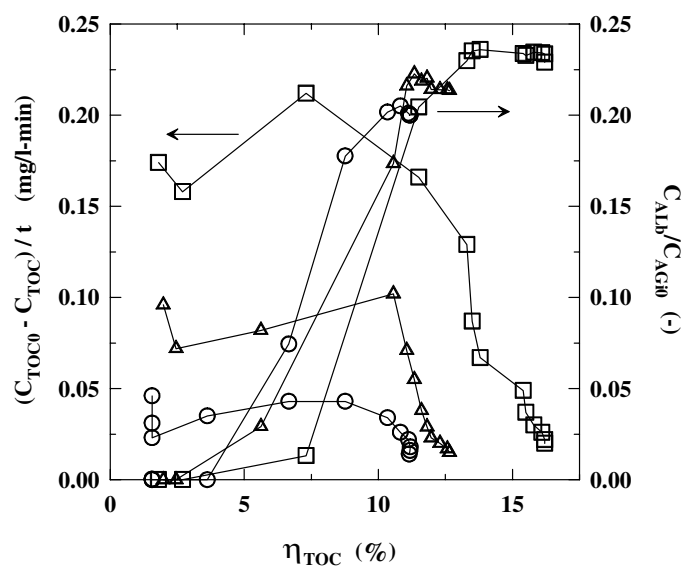

Fig. 7. $\left(C_{\mathrm{TOC} 0}-C_{\mathrm{TOC}}\right) / t$ and $C_{\mathrm{ALb}} / C_{\mathrm{AGi} 0}$ vs. $\eta_{\mathrm{TOC}}$ for ozonation of 2-MT in semibatch system. Notations are the same as specified in Fig. 4. 
remarkably lower than $0.02 \mathrm{mg}^{-1} \mathrm{~min}^{-1}$ with the higher $\eta_{\text {TOC }}$. Comparing with the results of the ozonation of 2-naphthalenesulfonate with $C_{\mathrm{AGi} 0}=11$ and $44 \mathrm{mgl}^{-1}$ reported by Chen et al. (2002), which reported the values of $\left(C_{\text {TOC } 0}-C_{\text {TOC }}\right) / t=0.27-1.64 \mathrm{mg} \mathrm{l}^{-1} \mathrm{~min}^{-1}$ for $\eta_{\mathrm{TOC}}=0-100 \%$ with $C_{\mathrm{TOC} 0}=104 \mathrm{mg} \mathrm{l}^{-1}$, we note that the mineralization rate of $2-\mathrm{MT}$ ozonation is relatively low. The comparison indicates that the organic compound with the heterocyclic structure is more resistant to the ozonation than that with the benzene ring.

The variation of $C_{\mathrm{ALb}} / C_{\mathrm{AGi} 0}$ with $\eta_{\mathrm{TOC}}$ is also shown in Fig. 7. It is seen that the value of $C_{\mathrm{ALb}} / C_{\mathrm{AGi}}$ remains low for $\eta_{\mathrm{TOC}}<5 \%$, but rapidly increases as $\eta_{\text {TOC }}$ increases from $5 \%$ to $10 \%$. The $C_{\mathrm{AGi} 0} / C_{\mathrm{ALb}}$ (inverse of $\left.C_{\mathrm{ALb}} / C_{\mathrm{AGi0}}\right)$ approaches to the steady state value of $4.62 \pm 0.32$ as $\eta_{\text {TOC }}>10 \%$, which is close to the Henry's constant of ozone $\left(H_{\mathrm{A}}\right)$ at $298 \mathrm{~K}$ with values between 3.34 and 4.78 reported by Chiu et al. (1997). The low ozone consumption also indicates the inactivation of the ozonation products. Moreover, the masses of ozone applied $\left(m_{\mathrm{O}_{3} \mathrm{~A}}\right)$ and consumed by chemical reactions $\left(m_{\mathrm{O}_{3} \mathrm{R}}\right)$ are defined by Eqs. (1) and (2), respectively. The mathematic derivation of Eq. (2) is shown in detail in Appendix A.

$m_{\mathrm{O}_{3} \mathrm{~A}}=Q_{\mathrm{G}} \times C_{\mathrm{AGi} 0} \times t$

$m_{\mathrm{O}_{3} \mathrm{R}}=\int_{0}^{t} Q_{\mathrm{G}}\left(C_{\mathrm{AGi} 0}-C_{\mathrm{AGe}}\right) \mathrm{d} t-C_{\mathrm{ALb}} V_{\mathrm{L}}-C_{\mathrm{AGe}} V_{\mathrm{F}}$

In Eqs. (1) and (2), $V_{\mathrm{L}}$ and $V_{\mathrm{F}}$ are the volumes of solution and free space in the reactor, respectively.

Fig. 8 illustrates the variations of $Y_{\mathrm{SO}_{4}^{2-}}$ and $m_{\mathrm{O}_{3} \mathrm{~A}} /$ $\left(C_{\mathrm{B} 0} V_{\mathrm{L}}\right)\left(\mathrm{mol} \mathrm{mol}^{-1}\right)$ with $m_{\mathrm{O}_{3} \mathrm{R}} /\left(C_{\mathrm{B} 0} V_{\mathrm{L}}\right)\left(\mathrm{mol} \mathrm{mol}^{-1}\right)$. The $m_{\mathrm{O}_{3} \mathrm{~A}} /\left(C_{\mathrm{B} 0} V_{\mathrm{L}}\right)$ and $m_{\mathrm{O}_{3} \mathrm{R}} /\left(C_{\mathrm{B} 0} V_{\mathrm{L}}\right)$ denote the mole ratios of ozone applied and consumed to the 2-MT treated, respectively. The results indicate that the value of $Y_{\mathrm{SO}_{4}^{2-}}$ is approximately proportional to $m_{\mathrm{O}_{3} \mathrm{R}} /\left(C_{\mathrm{B} 0} V_{\mathrm{L}}\right)$ when $m_{\mathrm{O}_{3} \mathrm{R}} /\left(C_{\mathrm{B} 0} V_{\mathrm{L}}\right)<4$. The ratio of $Y_{\mathrm{SO}_{4}^{2-}}$ to $m_{\mathrm{O}_{3} \mathrm{R}} /$ $\left(C_{\mathrm{B} 0} V_{\mathrm{L}}\right)$ is about $0.11 \%$ in this region. As $m_{\mathrm{O}_{3} \mathrm{R}} /\left(C_{\mathrm{B} 0} V_{\mathrm{L}}\right)$ increases higher than 5 , the value of $Y_{\mathrm{SO}_{4}^{2-}}$ reaches a constant value of about $47 \%$. Furthermore, Fig. 8 describes the association of $m_{\mathrm{O}_{3} \mathrm{~A}}$ with $m_{\mathrm{O}_{3} \mathrm{R}}$, where the value of $m_{\mathrm{O}_{3} \mathrm{R}} / m_{\mathrm{O}_{3} \mathrm{~A}}$ represents the efficiency of ozone utilization. The values of $m_{\mathrm{O}_{3} \mathrm{R}} / m_{\mathrm{O}_{3} \mathrm{~A}}$ are high when $m_{\mathrm{O}_{3} \mathrm{R}} /\left(C_{\mathrm{B} 0} V_{\mathrm{L}}\right)<4$ and similar for various concentrations of input ozone. In the region with $m_{\mathrm{O}_{3} \mathrm{R}} /\left(C_{\mathrm{B} 0} V_{\mathrm{L}}\right)<4$, the efficiency of ozone utilization is greater than $51 \%$. However, the value of $m_{\mathrm{O}_{3} \mathrm{R}} / m_{\mathrm{O}_{3} \mathrm{~A}}$ decreases significantly when $m_{\mathrm{O}_{3} \mathrm{R}} /\left(C_{\mathrm{B} 0} V_{\mathrm{L}}\right)>4$, indicating the low reactivity of subsequent intermediates with ozone. The efficiency of ozone utilization becomes smaller than $10 \%$ when $m_{\mathrm{O}_{3} \mathrm{R}} /\left(C_{\mathrm{B} 0} V_{\mathrm{L}}\right)>7$.

In summary, the ozonation treatment is effective for the decomposition of 2-MT in the aqueous solution. The

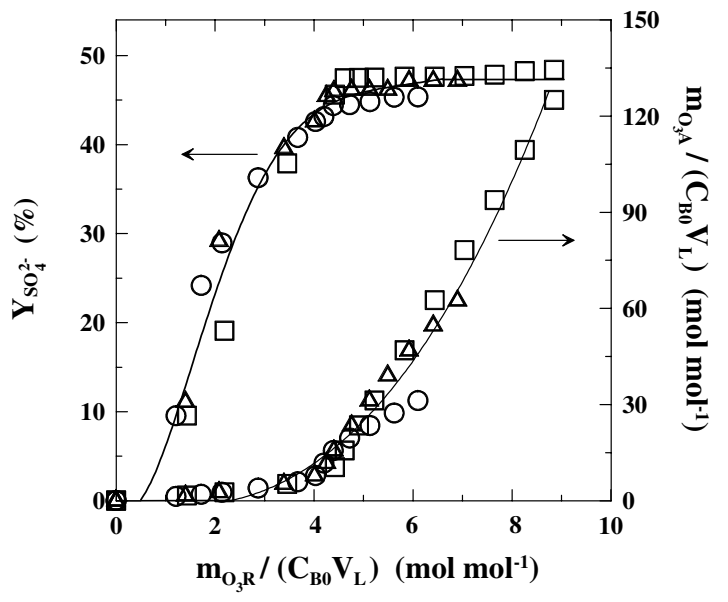

Fig. 8. $Y_{\mathrm{SO}_{4}^{2-}}$ and $m_{\mathrm{O}_{3} \mathrm{~A}} /\left(C_{\mathrm{B} 0} V_{\mathrm{L}}\right)$ vs. $m_{\mathrm{O}_{3} \mathrm{R}} /\left(C_{\mathrm{B} 0} V_{\mathrm{L}}\right)$ for ozonation of 2-MT in semibatch system. Notations are the same as specified in Fig. 4. - : polynomial curve fitting of experimental data. $Y_{\mathrm{SO}_{4}^{2-}}$ and $m_{\mathrm{O}_{3} \mathrm{~A}} /\left(C_{\mathrm{B} 0} V_{\mathrm{L}}\right): R^{2}=0.986$ and 0.978 .

enhancing effect of ozone dosage on the decomposition rate of 2-MT is remarkable. However, the ozonation alone cannot achieve a complete mineralization of 2MT. The nitrogen and sulfur atoms on the heterocyclic ring of 2-MT are hard to be oxidized to form nitrate and sulfate. The results obtained in this study are useful for the proper design of the ozonation treatment of 2-MT in the aqueous solution.

\section{Conclusions}

1. Ozonation is employed as an effective way for the decomposition of 2-mercaptothiazoline (2-MT) in the aqueous solution. The decomposition of 2-MT takes place accompanied with the formation of sulfate and ammonium, the diminution of total organic carbons (TOCs), and the consumption of ozone $\left(m_{\mathrm{O}_{3} \mathrm{R}}\right)$.

2. The rates of decomposition of 2-MT, generation of sulfate, and elimination of TOC increase significantly with the input ozone dosage. When the decomposition of 2-MT is completed, the remarkable yield of sulfate $\left(Y_{\mathrm{SO}_{4}^{2-}}\right)$ and the low removal efficiency of TOC $\left(\eta_{\text {TOC }}\right)$ are about $24 \%$ and $2.3 \%$, respectively.

3. The values of $Y_{\mathrm{SO}_{4}^{2-}}$ during the ozonation of 2-MT have apparent relationships with $\eta_{\mathrm{TOC}}$ and $m_{\mathrm{O}_{3} \mathrm{R}} /$ $C_{\mathrm{B} 0} V_{\mathrm{L}}$, respectively. The $Y_{\mathrm{SO}_{4}^{2-}}$ and $\eta_{\mathrm{TOC}}$ for the ozonation of 2-MT have the maximum values of about $48 \%$ and $16 \%$, respectively. Furthermore, the nitrogen and sulfur atoms on the heterocyclic structure of 2-MT are found hard to be oxidized to form nitrate and sulfate. 
4. In the early period of ozonation, say $\eta_{\mathrm{TOC}}<10 \%$, the elimination rate of TOC is remarkably enhanced by the input ozone dosage with higher efficiency of ozone utilization. However, in the later period of ozonation, the successive intermediates show the low mineralization rate and efficiency of ozone utilization accompanied with the accumulation of the dissolved ozone. The results reveal that the products generated from the ozonation of 2-MT are evidently resistant toward further oxidation by ozone.

\section{Acknowledgements}

This study was supported by the National Science Council of Taiwan under Grant No. NSC 89-2211-E002-107.

\section{Appendix A. Mathematic derivation of Eq. (2)}

The governing equations of mass balance of ozone in a semibatch stirred vessel, which simultaneously consider the gas-liquid mass transfer, chemical reactions, and gas flow convection, can be described by Eqs. (A.1)-(A.3) according to the previous studies of $\mathrm{Wu}$ and Masten (2001) and Chiu et al. (2003). The proper assumptions of the model are listed as follows (Anselmi et al., 1984, 1985; Chiu et al., 1997, 2003).

1. The homogenous conditions are valid for the bulk liquid, holdup gas, and free space.

2. Henry's law applies.

3. Chemical reactions in gas phase are neglected.

For the ozone balance in liquid phase:

$$
\begin{aligned}
V_{\mathrm{L}}\left(\mathrm{d} C_{\mathrm{ALb}} / \mathrm{d} t\right)= & E_{\mathrm{rA}} k_{\mathrm{LA}}^{0} a\left(V_{\mathrm{L}}+V_{\mathrm{H}}\right)\left(C_{\mathrm{AGi}} / H_{\mathrm{A}}-C_{\mathrm{ALb}}\right) \\
& -\sum_{\text {by reactions }} \text { consumption rates of ozone }
\end{aligned}
$$

For the ozone balance in holdup gas:

$$
\begin{aligned}
V_{\mathrm{H}}\left(\mathrm{d} C_{\mathrm{AGi}} / \mathrm{d} t\right)= & Q_{\mathrm{G}}\left(C_{\mathrm{AGi} 0}-C_{\mathrm{AGi}}\right)-E_{\mathrm{rA}} k_{\mathrm{LA}}^{0} a\left(V_{\mathrm{L}}+V_{\mathrm{H}}\right) \\
& \times\left(C_{\mathrm{AGi}} / H_{\mathrm{A}}-C_{\mathrm{ALb}}\right)
\end{aligned}
$$

For the ozone balance in free space:

$$
V_{\mathrm{F}}\left(\mathrm{d} C_{\mathrm{AGe}} / \mathrm{d} t\right)=Q_{\mathrm{G}}\left(C_{\mathrm{AGi}}-C_{\mathrm{AGe}}\right)
$$

In the above equations, $C_{\mathrm{AGi}}, E_{\mathrm{rA}}, k_{\mathrm{LA}}^{0} a$, and $V_{\mathrm{H}}$ denote the ozone concentration in holdup gas, enhancement factor of ozone, volumetric mass transfer coefficient, and volume of holdup gas, respectively.

The initial conditions of Eqs. (A.1)-(A.3) are:

$t=0, \quad C_{\mathrm{ALb}}=C_{\mathrm{AGi}}=C_{\mathrm{AGe}}=0$
The sum of Eqs. (A.1)-(A.3) yields as Eq. (A.5):

$$
\begin{aligned}
V_{\mathrm{L}}\left(\mathrm{d} C_{\mathrm{ALb}} / \mathrm{d} t\right)+V_{\mathrm{H}}\left(\mathrm{d} C_{\mathrm{AGi}} / \mathrm{d} t\right)+V_{\mathrm{F}}\left(\mathrm{d} C_{\mathrm{AGe}} / \mathrm{d} t\right) \\
=Q_{\mathrm{G}}\left(C_{\mathrm{AGi} 0}-C_{\mathrm{AGe}}\right) \\
\quad-\sum \text { consumption rates of ozone by reactions }
\end{aligned}
$$

Furthermore, integrating Eq. (A.5) with respect to $t$ from 0 to $t$ gives

$$
\begin{aligned}
& V_{\mathrm{L}} C_{\mathrm{ALb}}+V_{\mathrm{H}} C_{\mathrm{AGi}}+V_{\mathrm{F}} C_{\mathrm{AGe}} \\
& =\int_{0}^{t} Q_{\mathrm{G}}\left(C_{\mathrm{AGi} 0}-C_{\mathrm{AGe}}\right) \mathrm{d} t-m_{\mathrm{O}_{3} \mathrm{R}}
\end{aligned}
$$

In Eq. (A.6), $m_{\mathrm{O}_{3} \mathrm{R}}=\int_{0}^{t}\left(\sum\right.$ consumption rates of ozone by reactions) $\mathrm{d} t$.

Accordingly, Eq. (A.6) can be simplified to Eq. (2) by neglecting the relatively small term of $V_{\mathrm{H}} C_{\mathrm{AGi}}$, which had been employed and justified in the previous study of Chen et al. (2002). Apparently, $m_{\mathrm{O}_{3} \mathrm{R}}$ depends only on the ozone consumption and can be calculated from the measurable values of $C_{\mathrm{ALb}}$ and $C_{\mathrm{AGe}}$. Thus, $m_{\mathrm{O}_{3} \mathrm{R}}$ can be used to assess the performance of ozonation under various experimental conditions.

\section{References}

Anselmi, G., Lignola, P.G., Raitano, C., Volpicelli, G., 1984. Ozone mass transfer in stirred vessel. Ozone Sci. Eng. 6, 1728.

Anselmi, G., Lignola, P.G., Raitano, C., Volpicelli, G., 1985. Ozone absorption with reaction in benzensulfonic acid aqueous solution. Chem. Eng. Sci. 40, 1033-1040.

Beltrán, F.J., Alvarez, P., 1996. Rate constant determination of ozone-organic fast reactions in water using an agitated cell. J. Environ. Sci. Health A 31, 1159-1178.

Chang, C.Y., Chen, Y.H., Li, H., Chiu, C.Y., Yu, Y.H., Chiang, P.C., Ku, Y., Chen, J.N., 2001. Kinetics of decomposition of polyethylene glycol in electroplating solution by ozonation with UV radiation. J. Environ. Eng., ASCE 127, 908-915.

Chen, Y.H., Chang, C.Y., Huang, S.F., Chiu, C.Y., Ji, D., Shang, N.C., Yu, Y.H., Chiang, P.C., Ku, Y., Chen, J.N., 2002. Decomposition of 2-naphthalenesulfonate in aqueous solution by ozonation with UV radiation. Water Res. 36, 4144-4154.

Chiu, C.Y., Chang, C.Y., Huang, W.H., Lee, S.J., Yu, Y.H., Liou, H.T., Ku, Y., Chen, J.N., 1997. A refined model for ozone mass transfer in a semibatch stirred vessel. Ozone Sci. Eng. 19, 439-456.

Chiu, C.Y., Chang, C.Y., Chen, Y.H., Yu, Y.H., Chiang, P.C., $\mathrm{Ku}, \mathrm{Y}$., 2003. Ozone mass transfer with combined effects of ozone decomposition and reaction with pollutants in a semibatch stirred vessel. J. Chin. Inst. Chem. Eng. (Taiwan) 34 (3), 281-289.

Fang, C.L., 1996. General Concepts of Additives in the Electroplating Solution. Finishing Science Pub. Co, Taipei, Taiwan. 
Fiehn, O., Wegener, G., Jochimshn, J., Jekel, M., 1998. Analysis of the ozonation of 2-mercaptobenzothiazole in water and tannery wastewater using sum parameters, liquid and gas chromatography and capillary electrophoresis. Water Res. 32, 1075-1084.

Gurol, M.D., Singer, P.C., 1982. Kinetics of ozone decomposition: a dynamic approach. Environ. Sci. Technol. 16, 377-383.

Hautaniemi, M., Kallas, J., Munter, R., Trapido, M., 1998. Modeling of chlorophenol treatment in aqueous solutions. 1. Ozonation and ozonation combined with UV radiation under acidic conditions. Ozone Sci. Eng. 20, 259-282.

Hoigné, J., Bader, H., Haag, W.R., Staehelin, J., 1985. Rate constants of reactions of ozone with organic and inorganic compounds in water. III. Inorganic compounds and radicals. Water Res. 18, 993-1004.

Koch, M., Yediler, A., Lienert, D., Insel, G., Kettrup, A., 2002. Ozonation of hydrolyzed azo dye reactive yellow 84 (CI). Chemosphere 46, 109-113.

Langlais, B., Reckhow, D.A., Brink, D.R., 1991. Ozone in Water Treatment. Application and Engineering. Lewis Publishers, Chelsea, MI, USA.

Lizarraga, M.E., Navarro, R., Urriolabeitia, E.P., 1997. Synthesis and characterization of dinuclear complexes of $\mathrm{Pd}^{\mathrm{II}}$ containing the $(\mu-\mathrm{N}-\mathrm{C}-\mathrm{S})_{2}$ skeleton. J. Organomet. Chem. $542,51-60$.

Mahal, H.S., Mukherjee, T., 1999. Kinetics and spectroscopic properties of intermediates formed by the reaction of some oxidizing and reducing radicals with 2-mercaptothiazoline
(2-MT) in aqueous solutions. Radiat. Phys. Chem. 54, 2937.

McCabe, W.L., Smith, J.C., Harriott, P., 1993. Unit Operations of Chemical Engineering. McGraw-Hill, New York, NY, USA.

Morel, F.M.M., Hering, J.G., 1993. Principles and Applications of Aquatic Chemistry. John Wiley and Sons, New York, NY, USA.

Rankness, K., Gordon, G., Langlais, B., Masschelein, W., Matsumoto, N., Richard, Y., Robson, C.M., Somiya, I., 1996. Guideline for measurement of ozone concentration in the process gas from an ozone generator. Ozone Sci. Eng. 18, 209-229.

Sotelo, J.L., Beltrán, F.J., Benítez, F.J., Beltrán-Heredia, J., 1987. Ozone decomposition in water: kinetic study. Ind. Eng. Chem. Res. 26, 39-43.

Wang, L., Yin, G.J., Yin, J.G., 2001. 2-Mercaptothiazoline and cetyl pyridinium chloride as inhibitors for the corrosion of a low carbon steel in phosphoric acid. Corros. Sci. 43, 11971202.

Wibaut, J.P., 1959. Ozonolysis of pyrroles, furans, and gammapyrones in connection with reactivity of bonds in ring system. In: The Staff of ACS, (Ed.), Ozone Chemistry and Technology. American Chemical Society, Washington, D.C., USA, pp. 153-161.

Wu, J.J., Masten, S.J., 2001. Mass transfer of ozone in semibatch stirred reactor. J. Environ. Eng., ASCE 127, 1089-1099. 